\title{
A comparative study of clinical and radiological outcome between cages and morselized bone graft in transforaminal lumbar interbody fusion surgery: a hospital-based study
}

\author{
Amit Jain ${ }^{1}$, Abhishek Chandra ${ }^{1 *}$, Aakanksha Agarwal'2, \\ Ramesh Chandra Meena', Mudit Agarwal ${ }^{3}$
}

\begin{abstract}
${ }^{1}$ Department of Orthopedics, ${ }^{2}$ Department of Radiodiagnosis, SMS Medical College, Jaipur, Rajasthan, India
${ }^{3}$ Intern, AIIMS, New Delhi, India
\end{abstract}

Received: 06 March 2020

Revised: 21 March 2020

Accepted: 24 March 2020

*Correspondence:

Dr. Abhishek Chandra,

E-mail: abhishekchandra.dr@gmail.com

Copyright: (c) the author(s), publisher and licensee Medip Academy. This is an open-access article distributed under the terms of the Creative Commons Attribution Non-Commercial License, which permits unrestricted non-commercial use, distribution, and reproduction in any medium, provided the original work is properly cited.

\begin{abstract}
Background: Degenerative spinal diseases resulting in neuropathic backache are managed by nerve root decompression with instrumented interbody fusion is the treatment of choice for these groups of patients when not managed conservatively.

Methods: Hospital based, comparative, retrospective study was carried out in such patients who underwent transforaminal lumbar interbody fusion (TLIF) with either cage with bone graft or stand-alone autologous morselized bone graft. The clinical and radiological outcomes were compared in these two methods of interbody fusion to assess any significant difference between them. A total of 20 patients with lumbar canal stenosis and degenerative grade $1 / 2$ spondylolisthesis who failed conservative management were operated by TLIF approach and were evaluated for postoperative improvement in Oswestry disability index (ODI) and interbody fusion on imaging at 6 months and 1 year postoperatively. Vertebral level of surgical intervention, intra-operative blood loss and duration of surgery were recorded for each patient along with complications, if any.

Results: In our study there was no significant difference in the clinical and radiological outcome between the two methods of interbody fusion. Although the group which was offered morselized bone graft with cage showed slightly better clinical outcome at 6 months of follow up, both showed no significant difference in ODI at 1 year of follow up. Conclusions: With this study, we can conclude that both the methods have similar clinical and radiological outcome with similar patient satisfaction and can be interchangeably employed for interbody fusion according to surgeon's and patient's preferences.
\end{abstract}

Keywords: Transforaminal lumbar interbody fusion, Morselized bone graft, Cage, Oswestry disability index

\section{INTRODUCTION}

With advancement of age, degenerative spinal diseases have become a common problem. Once called as a disease of aging, its incidence is gradually increasing in younger adults. Its spectrum includes degenerative disc disease, spinal stenosis, degenerative spinal scoliosis, facet joint arthritis and spondylolisthesis. ${ }^{1}$ Most commonly, patients present with backache, radicular pain and stiffness which results in variable degree of morbidity and are one of the most frequent causes of disability. Conservative management like physiotherapy, analgesics and life style modifications are usually advised as the $1^{\text {st }}$ line of 
treatment. Surgery is indicated in patients with symptomatic spondylolisthesis and spinal canal stenosis. ${ }^{2,3}$

The goal of surgery in degenerative spine disease is decompression of the involved nerve root with or without solid bony fusion. Instrumented lumbar fusion has become a common surgical practice for management of degenerative lumbar spine disease. ${ }^{4}$ It stabilizes the painful motion segment, and may provide indirect decompression of the neural elements. Success of the surgery depends upon adequate neural decompression, instrumentation, bone graft and proper disc space preparation. Various surgical techniques regarding approaches, instrumentation, graft material and site of lumber fusion are described in the literature. ${ }^{5}$ Various approaches for lumber interbody fusion are posterior lumbar interbody fusion (PLIF), transforaminal lumbar interbody fusion (TLIF), minimally invasive transforaminal lumbar interbody fusion (MI-TLIF), oblique lumbar interbody fusion/anterior to psoas (OLIF/ATP), lateral lumbar interbody fusion (LLIF) and anterior lumbar interbody fusion (ALIF).

TLIF is the most widely accepted procedure which was originally put forward by Harms and Rolinger in $1982 .{ }^{6}$ We conducted a retrospective comparative study between TLIF with stand-alone morselized impacted bone graft and TLIF with cage and bone graft to compare the clinical, functional and radiological outcomes. There is literature available describing advantages and disadvantages of TLIF with cage and bone graft, and only morselized bone graft, but there is limited literature comparing the two.

\section{METHODS}

\section{Patient selection}

We retrospectively studied 20 patients treated with TLIF between March 2016 and May 2017 with an average follow up of 12 months at the tertiary care government hospital SMS medical college in Jaipur, Rajasthan. 10 patients received TLIF with local morselized bone graft with cage (group 1) and the other 10 patients received the TLIF with local morselized bone graft without cage (group 2 ). The inclusion criteria for our study were severe spinal canal stenosis (based on pre-operative MRI showing more than $2 / 3^{\text {rd }}$ times reduction in AP diameter of canal and walking distance of less than $100 \mathrm{~m}$ based on self-paced walking test [SPWT] records), grade 1/2 listhesis and failed conservative management. Degenerative listhesis and lumbar canal stenosis can co-exist. Plain AP and lateral radiograph and MRI were used for identifying the involved motion segment and to evaluate the orientation, and width of the vertebral pedicle. The exclusion criteria in our study were spinal infection, severe osteoporosis, multilevel involvement and previous spinal surgery. Written and informed consent was taken from all patients for inclusion in the study.

\section{Surgical techniques}

All surgeries were performed by the same team of surgeons in the same clinical setting. Patient was placed in a prone position with adequate release of intra-abdominal pressure to decrease intra-operative bleeding and allow proper care of skin overlying the bony prominences. Before making the incision, correct level of involved vertebrae was assessed by help of fluoroscopic guidance. The lumbar spine was approached through a posterior midline incision. Paraspinal muscles were retracted from caudal to cephalad direction, from spinous process and lamina up to the transverse process. Identification of lamina, pars, facet joint and transverse process was done. Pedicle screws of appropriate size were then inserted under $\mathrm{C}$-arm guidance bilaterally. Rod was applied on the contralateral side and the disc space was distracted. Entry into the spinal canal was made after laminectomy and facetectomy on the side of the radicular pain. Resection of inferior facet of superior vertebrae and superior facet of inferior vertebrae was done to gain access to the disc and decompress the foramina. Exiting nerve route was then exposed. Epidural bleeding was commonly encountered at this point which was easily controlled using gel foam and bipolar cautery. Discectomy was performed and end plate preparation was done as follows. Using curettes, the cartilaginous coats of the end plates was removed intraoperatively without destroying the osseous structure of the end plates. Bone graft already harvested from local site was then cut into small pieces. In group 1, cage filled with local bone graft was inserted into the intervertebral disc space while in group 2, only bone graft was inserted into the intervertebral disc and impacted snugly. Then pedicle screw was inserted and rod system was applied on the contra-lateral side and compression achieved bilaterally. Wound closure was done in layers after placement of a drain which was removed after 2 days.

\section{Assessment}

Plain AP and lateral radiograph were taken at the preoperative, immediate post-operative and during follow up at $1.5,6$, and 12 months post-operatively. Radiographs were assessed for evidence of interbody fusion, screw loosening, and assessment of cage position and maintenance of disc height. Integrity of the pedicle screw -rod system was observed. Screw loosening was defined as a radio-luscency of $1 \mathrm{~mm}$ or greater at bone screw surface, and cage loosening was defined as a radiolucency of $1 \mathrm{~mm}$ or greater around the cage ${ }^{7}$. CT scan was used for assessment of bony fusion and each case was graded according to the fusion criteria, as described by Brantigan et $\mathrm{al}^{8}$, done at 1 year post-operatively. CT scan was also assessed for maintenance of disc height and implant loosening, fracture or subsidence. The radiological assessment was done by a single radiologist who was blinded to the clinical outcome.

Pre-operative, 6 months and one-year post-operative assessment of pain and disability was done. Pain was 
quantitatively assessed at each visit by VAS score. Duration of pain killer intake and time to return to normal physical activity was documented. Patient assessment questionnaires included Oswestry disability index (ODI) which was used to evaluate clinical improvements and daily functional outcome during follow up of the patients. ODI was calculated pre-operatively, at 6 months and 1 year post-operatively.

Intra-operative blood loss, duration of surgery, postoperative complications and duration of hospital stay was recorded for each case.

Statistical analysis for relevant data was done using SPSS software version 25. Mann Whitney test was employed to compare result in group 1 and group 2.

\section{RESULTS}

\section{Demographic data}

Out of the 20 cases, ratio of male: female was 3:2 in the first group (cage with bone graft) and 7:3 in the second group (morselized bone graft only). Average age of the patients was in 47.3 years (39-61 years) the group 1 and 52.4 years (34-63 years) in the group 2. The most common level involved in patients was L4-L5 in both the groups (Table 1 and 2).

\section{Radiological outcome}

Plain radiographs showed maintained disc heights in all patients with no evidence of screw loosening. Grade 5 solid bony fusion was achieved in all but 2 cases in both the groups. There was no implant fracture or subsidence (Figure 1). 8 out of 10 cases with cage with bone graft (group 1) had complete union on CT with 1 patient each having grade 3 and grade 4 fusion. In the case of morselized bone graft, 7 had complete fusion while three showed grade 4 fusion (Figure 2 and 3). Disc height was maintained in both the groups without any evidence of clinically significant collapse at 12 months of follow up.

\section{Clinical outcome}

Oswestry disability index showed relatively greater improvement in cases with cage with bone graft than morselized bone graft at 6 months post-operative follow but the difference was statistically insignificant $(\mathrm{p}>0.05)$. However, at 1 year of follow up, both groups showed equal improvement in ODI. All patients showed decrement in VAS score at 1-year follow-up.

\section{Per-operative outcome}

Average surgical time for cage with bone graft was 141 minutes while that for morselized bone graft was 122 minutes (Table 1 and 2). Average per operative blood loss in cases with cage with bone graft was $371.5 \mathrm{ml}$. Those with morselized bone graft had marginally lesser blood loss, averaging $308 \mathrm{ml}$. There was no clinically significant complication in any of the 20 cases. Two out of 10 cases in the first group and one out of 10 in the second group had a dural tear which was repaired intra-operatively and patient was place in Tredelenburg position. No superficial or deep infection was found in any patient post operatively and during follow up.

Table 1: Demographic data and outcome in group 1 (morselized bone graft with cage) $(n=10)$.

\begin{tabular}{|l|l|}
\hline Variable & \multicolumn{1}{l|}{ Values } \\
\hline Average age & \multicolumn{1}{l|}{ years } \\
\hline Sex distribution & 6 \\
\hline Males & 4 \\
\hline Females & \\
\hline Level involved & 7 \\
\hline L4-L5 & 3 \\
\hline L5-S1 & \\
\hline Grade of listhesis & 8 \\
\hline Grade I & 2 \\
\hline Grade II & 141 minutes \\
\hline Average intraoperative time & 371.5 ml \\
\hline Average blood loss & \\
\hline $\begin{array}{l}\text { Grade of fusion achieved at 1 } \\
\text { year follow up }\end{array}$ & 1 \\
\hline Grade 3 & 1 \\
\hline Grade 4 & 8 \\
\hline Grade 5 & 53.6 (SD 8.527) \\
\hline ODI pre-operative & 22.8 (SD 4.237) \\
\hline ODI at 6 months & 21 (SD 4.546) \\
\hline ODI at 12 months & \\
\hline
\end{tabular}

Table 2: Demographic data and outcome in group 2 (morselized bone graft without cage) $(n=10)$.

\begin{tabular}{|ll|}
\hline Variable & Values \\
\hline Average age & 52.4 years \\
\hline Sex distribution & \\
\hline Males & 7 \\
\hline Females & 3 \\
\hline Level involved & 7 \\
\hline L4-L5 & 3 \\
\hline L5-S1 & \\
\hline Grade of listhesis & 7 \\
\hline Grade I & 3 \\
\hline Grade II & 122 minutes \\
\hline Average intraoperative time & 308 ml \\
\hline Average blood loss & \\
\hline $\begin{array}{l}\text { Grade of fusion achieved at 1 } \\
\text { year follow up }\end{array}$ & Nil \\
\hline Grade 3 & 3 \\
\hline Grade 4 & 7 \\
\hline Grade 5 & 53.8 (SD 7.39) \\
\hline ODI pre- operative & 26 (SD 5.416) \\
\hline ODI at 6 months & 22.8 (SD 3.55) \\
\hline ODI at 12 months & \\
\hline
\end{tabular}




\section{ODI score assessment}

The mean pre-operative ODI in group 1 was 53.6 (SD8.527) while in group 2 was 53.8 (SD-7.39). Postoperative assessment at 6 months showed no significant difference between the two with mean value of 22.8 (SD4.237) in group 1 and 26 (SD- 5.416) in group 2. At 1 year of follow up, the mean ODI value in group 1 was 21 (SD4.546) and in group 2 was 22.8 (SD- 3.55) (Figure 1).

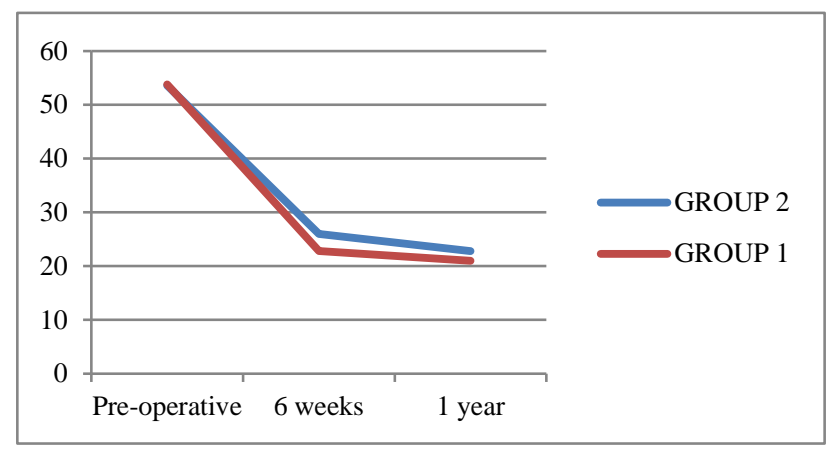

Figure 1: Comparative ODI in the two groups: group 1 (cage with bone graft) and group 2 (only morselized autologous bone graft).

\section{Cost}

Patients who underwent TLIF with cage with bone graft had a higher financial burden due to the cost of cage involved, averaging INR 10000 in our setup.

\section{DISCUSSION}

Degenerative lumbar spinal problems are commonly encountered in the aging population. Conservative management is the $1^{\text {st }}$ line of treatment. Surgery is indicated when conservative management is ineffective. The goal of surgery is decompression of nerve root, solid fusion and restoration of disc space height. Solid fusion results in better functional outcome and patient satisfaction. ${ }^{9}$

There are various types of fusion techniques practiced postero-lateral inter-transverse, anterior inter-body fusion and posterior interbody fusion. Posterior interbody fusion and posterolateral fusion are the most common treatment methods for lumbar spondylolisthesis. Studies have shown that PLIF exhibits a higher rate of fusion than does lumbar posterolateral fusion (PLF) and may produce better clinical outcomes. In this study, we have performed interbody fusion in all cases. Approaches available for interbody fusion technique range from anterior, oblique, transforaminal, posterior to minimally invasive lumbar interbody fusion.

Prior studies show better outcome in TLIF (transforaminal lumbar interbody fusion) in terms of decreased surgery time, blood loss and complication rates, and is thus our choice for all cases in this study. ${ }^{10}$

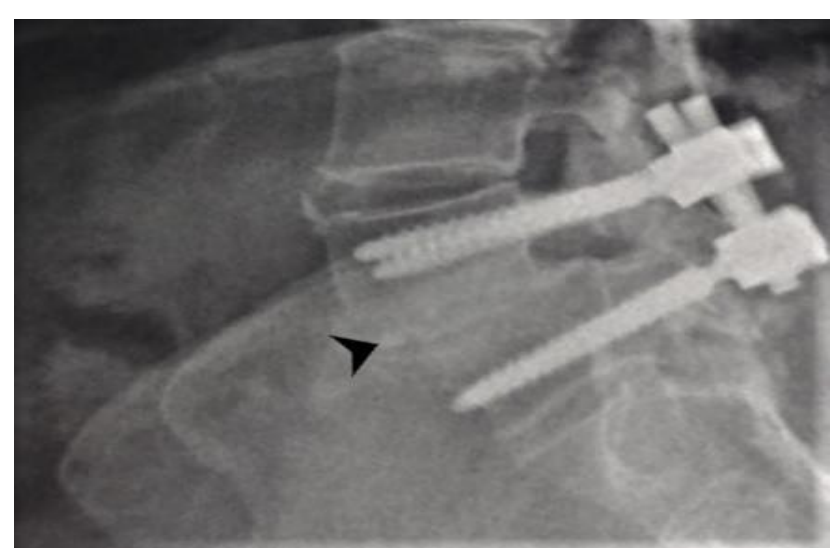

Figure 2a: Post-operative plain radiograph of patient from group 2 showing complete solid bony fusion (black arrowhead) with maintained disc height. There is no evidence of screw loosening.

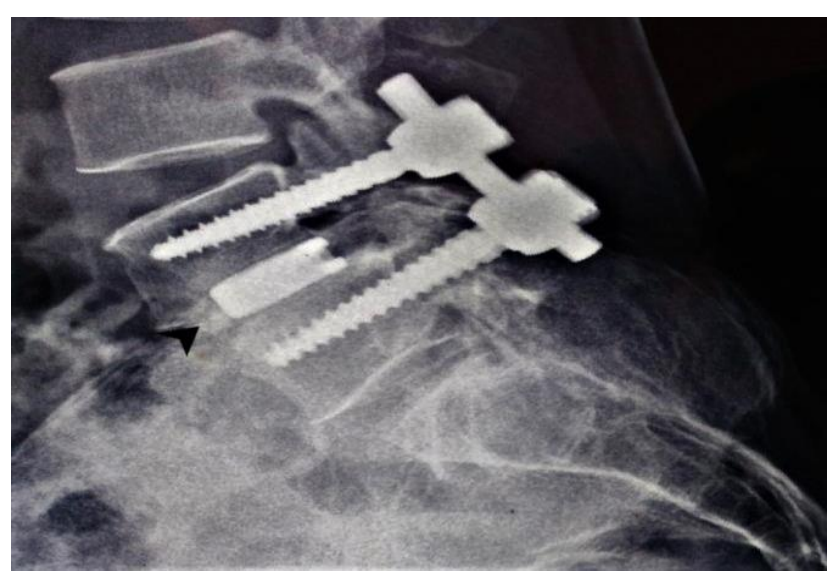

Figure 2b: Post-operative plain radiograph of patient from group 1 showing grade 3 fusion with solid new bone (black arrowhead) showing partial bridging of the intervertebral disc space.

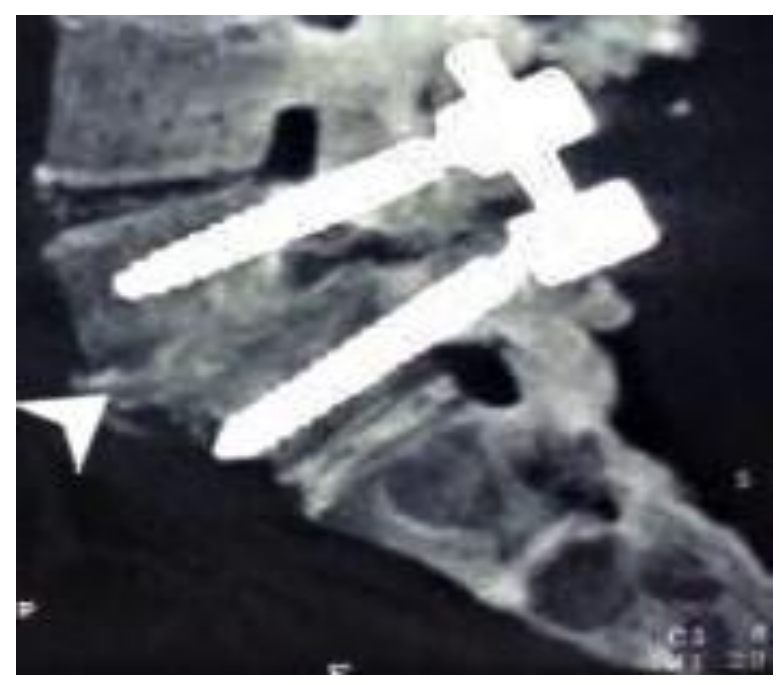

Figure 3a: Sagittal CT of patient from group 2 showing complete solid grade 5 bony fusion (white arrowhead) with maintained disc height. 


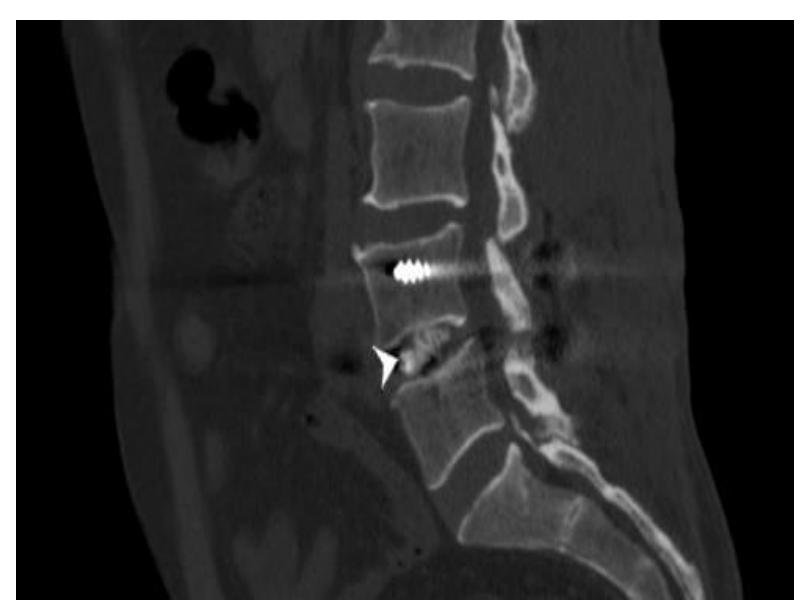

Figure 3b: Sagittal CT of patient from group 2 showing grade 4 fusion with almost complete bridging of the vertebral disc space (white arrowhead).

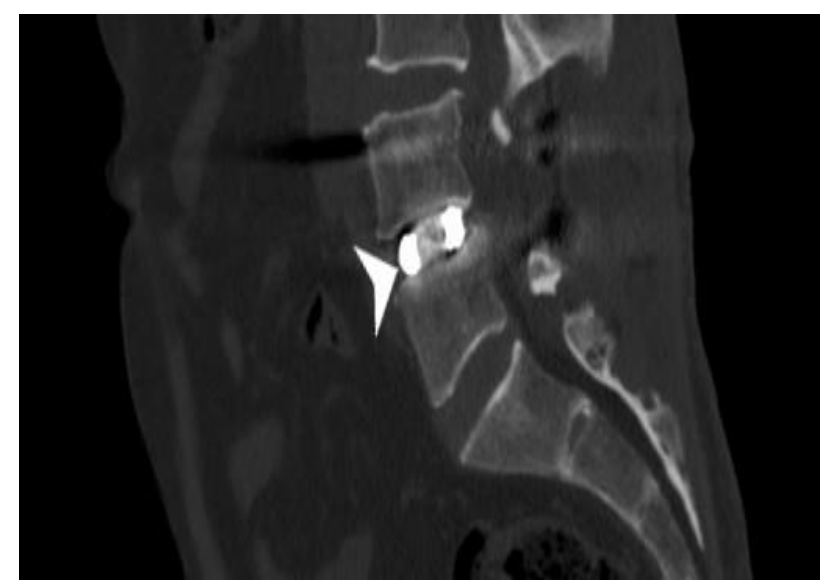

Figure 3c: Sagittal CT of patient from group 1 showing grade 5 fusion with complete bridging of the vertebral disc space (white arrowhead) by new bone formed within the cage.

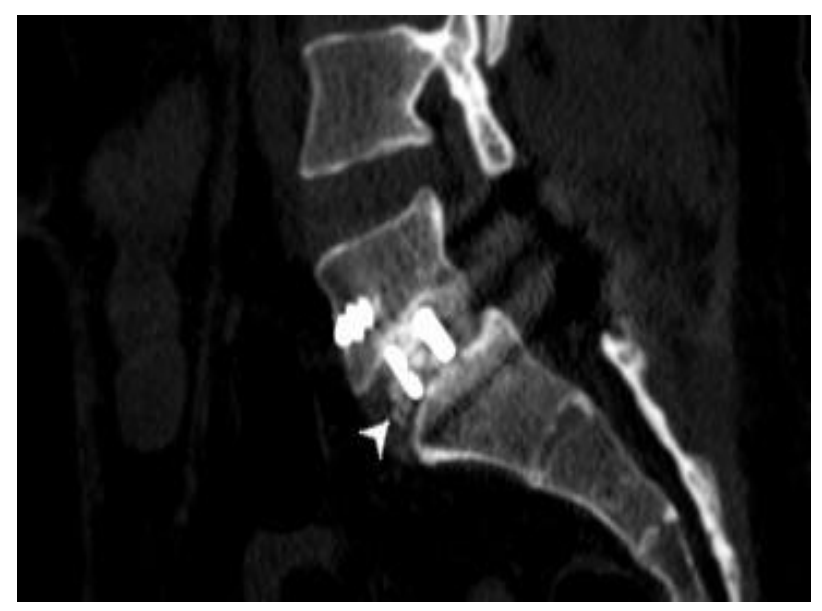

Figure 3d: Sagittal CT of patient from group 1 showing grade 3 fusion with solid new bone (white arrowhead) showing partial bridging of the intervertebral disc space.

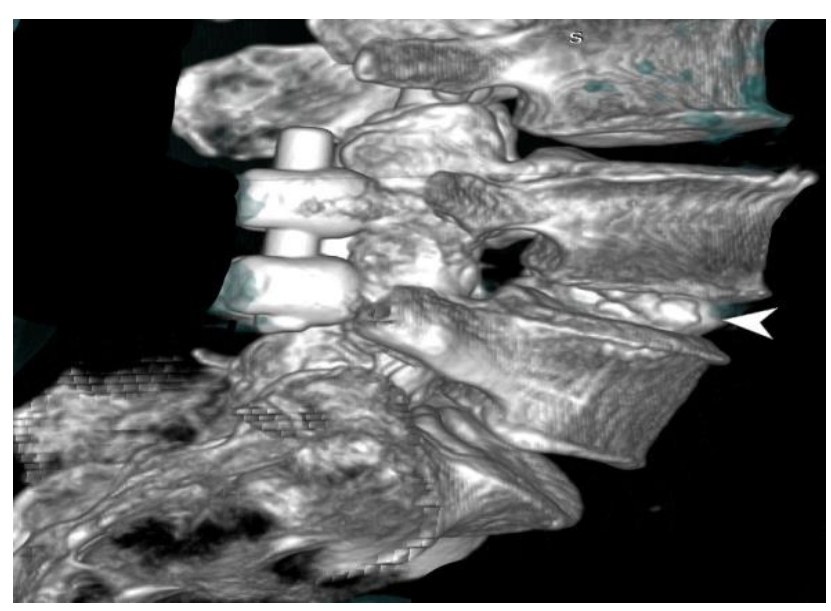

Figure 4a: 3D reconstructed CT image showing grade

4 fusion with almost complete bridging of the vertebral disc space (white arrowhead) in a patient from group 1.

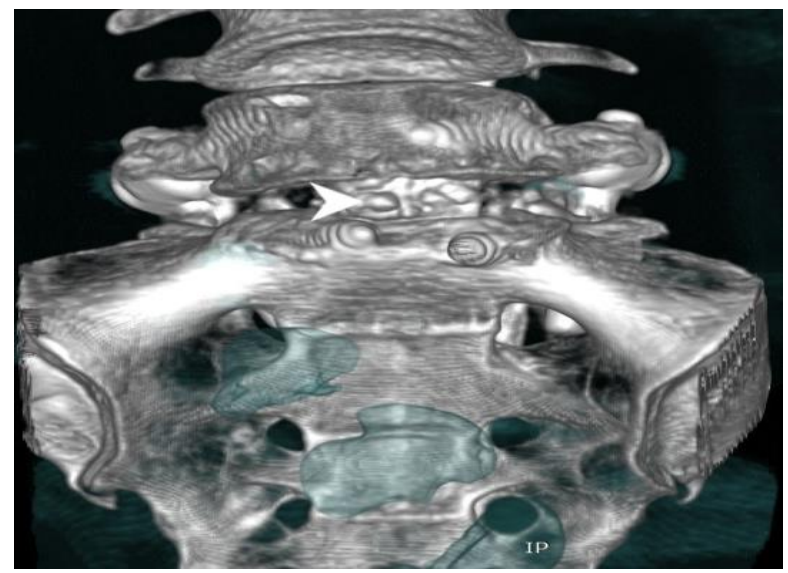

Figure 4b: 3D reconstructed CT image showing grade 3 fusion with solid new bone (white arrowhead) showing partial bridging of the intervertebral disc space in a patient from group 1.

Surgical success depends upon adequate neural decompression, instrumentation, and bone graft material and disc space preparation. ${ }^{11}$ Advancements in instrumentation like using pedicle screw along with bone graft/cage helps in increased fusion rate decreased rehabilitation time and improved functional outcome. ${ }^{12}$ Ideal bone graft material is one which has the least donor morbidity and provides maximum efficacy of bone growth by combining osteoinduction, osteoconduction and osteoblastic properties. ${ }^{13}$ Since the inception of the TLIF procedure, iliac crest bone graft was considered as an ideal graft material both in terms of quality and quantity and has traditionally been used for degenerative spine disease but it had complications like donor site pain, pelvic instability, infection, pelvic fracture, increased surgery time and blood loss. Morselized local bone graft has also proved to be as beneficial as autologous iliac bone graft, it also circumvent the complications and morbidity of harvesting bone graft 
from iliac crest, hence it is the preferred choice of bone graft in author's practice. ${ }^{14}$

According to isolated studies on cases of spondylolisthesis managed with interbody fusion with cage and bone graft, cage provides immediate anterior interbody support improves lumbar lordosis and provides better maintenance of disc height until bony fusion occurs due to the structural integrity. ${ }^{15,16}$ However, there is possibility of root injury, more intra-operative blood loss, retropulsion or migration of cage in the post-operative period, immunological issues due to foreign body reactions and lower fusion rate due to decreased available contact area for bony fusion. ${ }^{17-20}$ Implantation of cage in interbody space may demand greater resection of facets. Also, cage adds to the cost of implants leading to higher surgical packages.

Advantages of using isolated bone graft are higher fusion rates and lower cost but it does not provide immediate anterior inter body support and restoration of disc height. Using bone graft with pedicle screw provides a more rigid construct and anterior structural support during early postoperative stages. ${ }^{21}$

Comparative literature between isolated bone graft and bone graft with cage is limited with conflicting results like Abdul et al found that improvement in VAS score and increment in disc height was better in cage group while Patil et al found that excellent clinical and radiological outcome was achieved in isolated bone graft group. ${ }^{22,23} \mathrm{Yu}$ et al showed that the intervertebral height can be better maintained when using the cage technique. ${ }^{24}$ Arai et al used an autologous ileum graft for PLIF. ${ }^{25} 50 \%$ of the patients exhibited fusion after intervertebral space collapse, while none of the PLIF patients with a cage experienced intervertebral space collapse in his study. We performed a comparative study between isolated morselized bone graft and bone graft with cage to assess clinical and radiological outcome in patients with spondylolisthesis and stenosis managed by TLIF surgery who were divided into two groups depending upon patient preferences and financial condition.

In our study there was no significant difference in the clinical and radiological outcome between the two methods of interbody fusion. Although group 1 showed slightly better clinical outcome at 6 months of follow up, both depicted equal percentage of grade 5 fusion at 1 year of follow up.

\section{Limitation}

A small sample sizes, short duration of follow up and inclusion of single vertebral disc level involvement are the limitations of our study.

\section{CONCLUSION}

On comparing the two groups, there was no statistically significant difference $(\mathrm{p}>0.05)$ at 1 year of follow up based on ODI score. However, usage of cage added to extra financial burden to the patient which is a significant factor for consideration of use in TLIF surgery in a developing country. In summary, morselized bone grafts is as effective as cage with bone graft in providing improvement in symptoms and have similar clinical outcomes. Either can be used as an effective method for spinal fusion in single level TLIF surgery. The choice may depend on the operating surgeon, the patient's financial status and hospital protocols.

\section{Funding: No funding sources \\ Conflict of interest: None declared \\ Ethical approval: The study was approved by the institutional ethics committee}

\section{REFERENCES}

1. Middleton K, Fish DE. Lumbar spondylosis: Clinical presentation and treatment approaches. Curr Rev Musculoskeletal Med. 2009;2:94-104.

2. Mummaneni PV, Haid RW, Rodts GE. Lumbar interbody fusion: State-of-the-art technical advances. J Neurosurg Spine. 2004;1:24-30.

3. Lin PM. Posterior lumbar interbody fusion technique: Complications and pitfalls. Clin Orthop Relat Res. 1985;193:90-102.

4. Bridwell KH, Sedgewick TA, Brien MF, Lenke LG, Baldus $\mathrm{C}$. The role of fusion and instrumentation in the treatment of degenerative spondylolisthesis with spinal stenosis. J Spinal Disord. 1993;6:461-72.

5. Hanley EN, David SM. Current concepts reviewlumbar arthrodesis for the treatment of back pain. JBJS. 1999;5:716-30.

6. Harms J, Rolinger H. A one-stager procedure in operative treatment of spondylolisthesis: dorsal traction-reposition and anterior fusion (author's transl). Z Orthop Ihre Grenzgeb. 1982;20(3):343-7.

7. Sanden, Bengt, Olerud, Claes, Johansson C, Larsson $\mathrm{S}$, et al. The significance of radiolucent zones surrounding pedicle screws. Definition of screw loosening in spinal instrumentation. The Journal of bone and joint surgery. British Volume. 2004;86:457-61.

8. Brantigan JW, Steffee AD. A carbon fibre implant to aid interbody lumbar fusion. Two-year clinical results in the first 26 patients. Spine. 1993;18:210617.

9. $\mathrm{Yu} \mathrm{CH}$, Wang CT, Chen PQ. Instrumented posterior lumbar interbody fusion in adult spondylolisthesis. Clin Orthop Relat Res. 2008;466(12):3034-43.

10. Liu X, Wang Y, Qiu G, Weng X, Yu B, A systematic review withmeta-analysis of posterior interbody fusion versus posterolateral fusion inlumbar spondylolisthesis. Eur Spine J. 2014;23:43-56.

11. Musluman AM, Yilmaz A, Cansever T, Cavus H, Colak I, Genc HA, et al. Posterior lumbar interbody fusion versus posterolateral fusion with instrumentation in the treatment of low-grade isthmic 
spondylolisthesis: midterm clinical outcomes. J. Neurosurg Spine. 2011;14:488-96.

12. Sakeb N, Ahsan K. Comparison of the early results of transforaminal lumbar interbody fusion and posterior lumbar interbody fusion in symptomatic lumbar instability. Indian J Orthop. 2013;47:255-63.

13. Okuyama K, Kido T, Unoki E. PLIF with a titanium cage and excised facet joint bone for degenerative spondylolisthesis in augmentation with a pedicle screw. J Spinal Disord Tech. 2007;20:53-9.

14. Zdeblick TA. A prospective randomized study of lumbar fusion: preliminary results. Spine. 1993;18:983-91.

15. Ploumis A, Albert TJ, Brown Z, Mehbod AA, Transfeldt EE. Healos graft carrier with bone marrow aspirate instead of allograft as adjunct to local autograft for posterolateral fusion in degenerative lumbar scoliosis: a minimum 2-year follow-up study. J Neurosurg Spine. 2010;13(2):211-5.

16. Ito Z, Matsuyama Y, Sakai Y. Bone union rate with autologous iliac bone versus local bone graft in posterior lumbar interbody fusion. Spine. 2010;35(21):1101-5.

17. Patil SS, Rawall S, Nagad P. Outcome of single level instrumented posterior lumbar interbody fusion using corticocancellous laminectomy bone chips. Indian J Orthop. 2011;45(6):500-3.

18. Zhong HZ. Comparing the early efficacies of autologous bone grafting and interbody fusion cages for treating degenerative lumbar instability in patients of different ages. Int Orthop. 2016;40(6):1211-8.

19. Oxland TR, Lund T. Biomechanics of stand-alone cages and cages in combination with posterior fixation: a literature review. Eur Spine J. 2000;9(1):95-101.

20. Chen L, Tang T, Yang H. Complications associated with posterior lumbar interbody fusion using Bagby and Kuslich method for treatment of spondylolisthesis. Chin Med J (Engl). 2003;116:99103.

21. Jockisch KA, Brown SA, Bauer TW, Merritt K. Biological response to chopped carbon fiber reinforced PEEK. J Biomed Master Res. 1992;26(2):133-46.

22. Atil SS, Rawall S, Nagad P. Outcome of single level instrumented posterior lumbar interbody fusion using corticocancellous laminectomy bone chips. Indian J Orthop. 2011;45(6):500-3.

23. Zhong HZ. Comparing the early efficacies of autologous bone grafting and interbody fusion cages for treating degenerative lumbar instability in patients of different ages. Int Orthop. 2016;40(6):1211-8.

24. Yu CH, Wang CT, Chen PQ. Instrumented posterior lumbar interbody fusion in adult spondylolisthesis. Clin Orthop Relat Res. 2008;466:3034-43.

25. Arai Y, Takahashi M, Kurosawa H, Shitoto K, Comparative study of iliac bonegraft and carbon cage with local bone graft in posterior lumbar interbody fusion. J Orthop Surg (Hong Kong). 2002;10:1-7.

Cite this article as: Jain A, Chandra A, Agarwal A, Meena RC, Agarwal M. A comparative study of clinical and radiological outcome between cages and morselized bone graft in transforaminal lumbar interbody fusion surgery: a hospital-based study. Int J Res Orthop 2020;6:492-8. 